\title{
10 Total Cinema as Mode of Production
}

\begin{abstract}
Chapter 10 examines Bazin's 'myth of total cinema' in light of a major trend in recent world cinema to focus on monumental landscapes, in films by Byambsuren Davaa and Luigi Falorni (The Story of the Weeping Camel) Ingen nulims, 2003), Abderrahmane Sissako (Timbuktu, 2014), Mikhail Zvyagintsev (Leviathan/Leviafan, 2014), Nuri Bilge Ceylan (Winter Sleep/ Kış uykusu, 2014), Cristina Gallego and Ciro Guerra (Birds of Passage/ Pájaros de verano, 2018), and Kleber Mendonça Filho and Juliano Dornelles (Bacurau, 2019). Taken together, these films testify to the remarkable convergence among filmmakers from the most disparate corners of the globe in resorting to expansive landscapes as a totalising cosmos and a sealed-off stage for the drama of existence, where realism manifests itself by means of real locations.
\end{abstract}

Keywords: Leviathan; The Story of the Weeping Camel; Bacurau; Winter Sleep; Birds of Passage; Timbuktu

This last chapter addresses an impulse pointing in the opposite direction to non-cinema (explored in Part I), that is, total cinema. In lieu of a cinema which, in order to acquire political value and the status of art, dissolves itself into real life, total cinema aspires to change life itself into film. In focus will be landscape films, or films in which landscapes are not only an attractive and imposing backdrop to the action, but the only universe available to humans and other animals inhabiting it. Examples of such films abound in recent world cinema, which makes the case studies selected here rather arbitrary. However, given the speed with which landscapes around the globe are transforming, even completely disappearing, in the face of climate change, deforestation, wars, migration, tourism, construction expansion and other factors, landscape films have naturally emerged as an urgent record of ephemeral vistas, with a curious spike in the year 2014, when several such films collected international awards; three of my six case studies

Nagib, L., Realist Cinema as World Cinema: Non-cinema, Intermedial Passages, Total Cinema. Amsterdam: Amsterdam University Press, 2020 DOI 10.5117/9789462987517_CH10 
date from that year. Taken together, these films testify to the remarkable convergence among filmmakers from the most disparate corners of the globe in resorting to expansive landscapes as a totalising cosmos and a sealed-off stage for the drama of existence. None of these films, listed here in chronological order, could be imagined without their outdoor settings: the Gobi desert in South Mongolia, in The Story of the Weeping Camel (Ingen nulims, Byambasuren Davaa and Luigi Falorni, 2003); the Sahel savannahs in Mauritania (standing for Mali), in Timbuktu (Abderrahmane Sissako, 2014); the rocky coast of the Kola peninsula, northwestern Russia, in Leviathan (Leviafan, Andrey Zvyagintsev, 2014); the extraordinary rock formations of Cappadocia, central Anatolia, Turkey, in Winter Sleep (Kış uykusu, Nuri Bilge Ceylan, 2014); the desert of the Guajira peninsula, in northern Colombia, in Birds of Passage (Pájaros de verano, Cristina Gallego and Ciro Guerra, 2018); and the Brazilian sertão, or northeastern scrubland outback, in Bacurau (Kleber Mendonça Filho and Juliano Dornelles, 2019). ${ }^{1}$

In all these films, the totalising impetus, expressed through the monumental scale of the landscape, combines with a desire for realism by means of real locations endowed with unique geological formations, vegetation, populations and fauna. These are not, however, necessarily at the service of documentary accuracy and in fact, in most of the films in focus here, real settings were redefined and renamed to suit the fictional plot, to which are added the changes effected by art design, framing, editing and special effects. For example, in Bacurau, the sertão announced at the beginning of the film as 'western Pernambuco state' is actually the Seridó sertão, in Pernambuco's neighbouring state of Rio Grande do Norte. Timbuktu, likewise, was not shot in the real Timbuktu city and surroundings, in Mali, due to safety concerns, but in Oualata, in the southeast of neighbouring Mauritania. Pribrezhny, where the story of Leviathan takes place, is a fictional town; the film's main photography took place in the towns of Teriberka, Kirovsk, Monghegorsk and Olenegorsk, around the city of Murmansk, on the Barents Sea coast. In Winter Sleep, the fictional plot based on a selection of Anton Chekhov's short stories, combined with a section of Dostoyevsky's novel The Brothers Karamazov, was transplanted from Russia to Turkey. It is in The Story of the Weeping Camel and Birds of Passage, both endowed with a

1 These are some of the main awards collected by the films in focus here: The Story of the Weeping Camel, nomination for an Oscar in the category of best documentary; Timbuktu, seven César awards, including best film; Leviathan, Golden Globe award for best foreign-language film; Winter Sleep, Palme d'Or at the Cannes Film Festival; Birds of Passage, Ariel Award for Best Ibero-American Film; Bacurau, Jury Prize, Cannes Film Festival. 
strong ethnographic motivation, where landscapes come closest to offering documentary evidence of a people and their culture, respectively the Wayúu in Colombia and the nomad shepherds in Mongolia, though even in these two films documentary fact and local legends are combined in a constructed plot. The question then arises of the extent to which the indexical realism of the landscape can survive the forcibly manipulative processes of film production and postproduction.

In this chapter, I shall tackle this question from different but interconnected perspectives. I shall start by considering the sine-qua-non requirement, at the origin of all these films, of real, outdoor locations, and the painstaking scouting process this invariably entails. I will then evaluate in all these films - with particular attention to Leviathan - whether these locations' qualify as 'landscape' as opposed to mere 'settings', as per Lefebvre's (2006) famous distinction, which defines landscape in cinema according to its degree of narrative 'autonomy' and 'spectacular' time.

Landscape as a concept has a long tradition in western philosophy, extending from Kant to Rancière, and I shall examine the conundrum between 'selection', 'ordering' and 'arranging', pertaining to the philosophical definition of landscape, and the totalising impetus akin to notions of 'nature', 'beauty' and the 'sublime' as they present themselves in the films in question. This will include a reflection on the ways in which landscapes in them acquire 'worldhood' (Yacavone 2015) by means of isolation and remoteness, which promotes a complete integration between habitat, fauna and flora. In all cases, however, the fabled, utopian, even mythical settings remain vulnerable to alien invaders whose presence produces a tear in their integrity allowing for issues of our time - political corruption, drug trafficking, destructive tourism, gun culture - to seep in and ultimately restore their indexical link with the real world. This is also, and most importantly, the process through which landscape reveals itself as a repository of history, where fiction, myth and legend combine into fact. Analyses of Timbuktu, Bacurau and Birds of Passage will substantiate these claims.

The chapter will then define the drive towards total cinema, in the films in focus here, as realist, but of a realism at the opposite end of Bazin's (1967) famous 'myth of total cinema', which he describes as the human desire for the 'reconstruction of a perfect illusion of the outside world' (1967: 20). I will argue that the totalising landscapes here are marked, instead, by realism as a mode of film production, one that requires the collection of evidence in the objective world in support of the facts narrated in the fable. As such, they appeal to the spectator's understanding of the reality at stake, rather than enhancing, through artifice, the illusion of reality as elicited by the 
cinematographic apparatus, in Baudry's (1986) foundational formula. In order to clarify my argument, I will first turn to Winter Sleep, in which Plato's allegory of the cave, used by Baudry to identify the moment of truth within and outside the cinematographic apparatus, receives literal expression as a defining feature of the landscape. Finally, I will focus on The Story of the Weeping Camel, which, by means of a perfectly integrated cosmos combining landscape, human and non-human animals, offers a miraculous symbiosis between legend and fact. Here, realism as mode of production ends up meeting Bazin's total realism at reception point through the back door, which he left conveniently open for cinema's return to the moment when it 'had not yet been invented' (Bazin 1967: 21).

\section{Real Locations as Landscape}

Finding real outdoor locations is described by all filmmakers in focus here as a pre-condition for their films, despite the arduous, time-consuming and costly scouting process they entail. For the makers of Leviathan, for example, as important as the characters in the film was the environment in which they lived, and for this reason, as Vassilieva (2018) points out,

it took [director Andrey] Zvyagintsev and [his DoP Mikail] Krichman four months to find the ideal location - having started in the countryside close to Moscow, they visited 75 small Russian towns before deciding on the small village of Teriberka on the Kolsky peninsula, and reworking the original script accordingly.

It must be noted that Teriberka is located more than two thousand kilometres away from Moscow, where the scouting began. This, for Vassilieva (2018), demonstrates that, with Leviathan, Zvyagintsev had moved 'from his earlier aesthetic of high modernism towards an aesthetic of realism, based on observation and accurate representation', despite the fact that the real locations were renamed in the fictional story.

Realism is, in turn, explicitly cited by Kleber Mendonça Filho, co-director of Bacurau, who states that the film shows 'the behaviour of many real places in Brazil. I can state this with conviction, after having driven 11 thousand kilometres to find a location together with Juliano [Dornelles, Bacurau's co-director]' (Molica and Motta 2019). This staggering figure (if correct or even just approximate) demonstrates the effort, not only to find the ideal setting - i.e. the village of Barra and surroundings, renamed Bacurau in the 
film - but also the appropriate cast, in part drawn from nearby villages. 'We needed to be very honest with the representation of that kind of place', states Mendonça Filho, who justifies the choice of local villagers to complement the mixed cast with the fact that 'they understood the story [...] they knew the type of situation' (Girish 2019).

The strong belonging between cast and place was also essential for the makers of The Story of the Weeping Camel, who, after travelling four thousand kilometres in the Gobi desert, finally found not only the perfect location, but 'the perfect family to channel this folkloric tale: four generations living together in one camp, including wise-and-wizened oldsters, young parents with movie-star looks and effortless grace, and three appealing children' (Winter 2004). The ten years' preparation for the shoot of Birds of Passage in the Wayúu territory in Colombia, with a Wayúu-heavy cast; the superb locations of Winter Sleep, where the population live not only on the land but inside the rocks in whose caves they install their houses; the close links between the Tuaregs and the desert expressed through their traditions and language, Tamasheq, as well as the Bambara-speaking population of the Sahel; in short, in all cases examined here it was first necessary to find the place and its related people for the plot to make sense. Even in the case of Leviathan, with a cast majorly composed of professional actors, DoP Krichman 'wanted the characters to live in that universe and allow the audience to appreciate it in every scene, not leave it in a blur' (apud Vassilieva 2018).

Real locations have been a staple in realist cinema since Visconti's foundational neorealist film Ossessione, examined in Chapter 8, in which the Po Valley settings were so decisive for the film's aesthetic composition, that they became a recurrent background in Italian cinema ever since. I would however, hesitate, to define Ossessione as a 'landscape' film given the settings' strong subordination to the operatic narrative taking place in the foreground. In the films in focus in this chapter, instead, settings have a prominence that changes characters and animals living in it into their extension, claiming their own power of attraction in parallel or even in competition with the main fictional plot. The often-cited chapter by Martin Lefebvre, 'Between Setting and Landscape in Cinema' (2006: 19ff), can help us understand how background settings may ascend to the status of landscape in film.

Lefebvre argues that, whereas in experimental cinema landscapes can occur without necessarily contributing to narrative progression or any narrative at all, in 'classical' cinema, everything must be subordinated to the narrative, including the settings. He starts by drawing on Laura Mulvey and her distinction between the diverging gazes elicited by men and women 
on screen, respectively an active and a contemplative gaze. On this basis, he devises two corresponding modes at work in landscape films, the narrative and the spectacular mode. Alternating on screen, these two modes allow the spectator to follow the story and pause at intervals to contemplate the spectacular landscape, which claims for itself a non-narrative or 'contemplative' time. As opposed to a film setting, a film landscape is thus endowed, in Lefebvre's view, with a double temporality, one as background to the narrative, and another as a spectacle in its own right. In sum, what defines a landscape in film is its 'autonomous' character.

Even though none of the films in this chapter can be classified as 'classical', along the lines of the strict rules described by David Bordwell et al in The Classical Holywood Cinema: Film Style \& Mode of Production to 1960 (1988), they are all narrative films, abiding by the rules of continuity, coherence, plausibility and verisimilitude. Thus Lefebvre's concept of the autonomous landscape applies entirely to them and helps us work through the hypothesis of total cinema as realism at the point of production. The opening of Leviathan is an eloquent example of this.

Still over the initial credits, and before any images are shown, the film starts with the help of another temporal medium, music, in the form of incisive and repetitive orchestral attacks, composed by minimalist Philip Glass, imposing itself as the originator of the tale. There follows a first landscape image in the form of a cliff of rocks taken from above, accompanied by the sound of waves crashing against them. As the music evolves, further expansive landscape shots are displayed in a sequence like a slideshow: sea and rocks, sea and a beach of boulders, sheer rocks, a lake surrounded by rocky peaks shot from two different angles, all taken with static camera. Then, gradually, signs of human activity start to emerge in the landscape, a decaying wooden harbour, derelict fishing boats, a long bridge seen from far above, a little motorboat passing under it, a house, the light in the house going on and finally a human being coming out of it, the protagonist Nikolai. As natural vistas are slowly replaced by manmade settings, non-diegetic music also recedes to let the local sounds of birds, dogs barking and the motorboat come to the fore and initiate storytelling. The principle governing the editing work in this opening indicates that fiction can only take place once a solid ground in an autonomous landscape, acquired through protracted duration, has been laid out. The 'spectacular' landscape, such as the vistas shown at the beginning, will continue to appear at regular intervals during the film, most prominently at the end, when a huge Orthodox Christian Church is unveiled at the top of the hill were Nikolai's house used to be. It was precisely the magnificent view onto the 


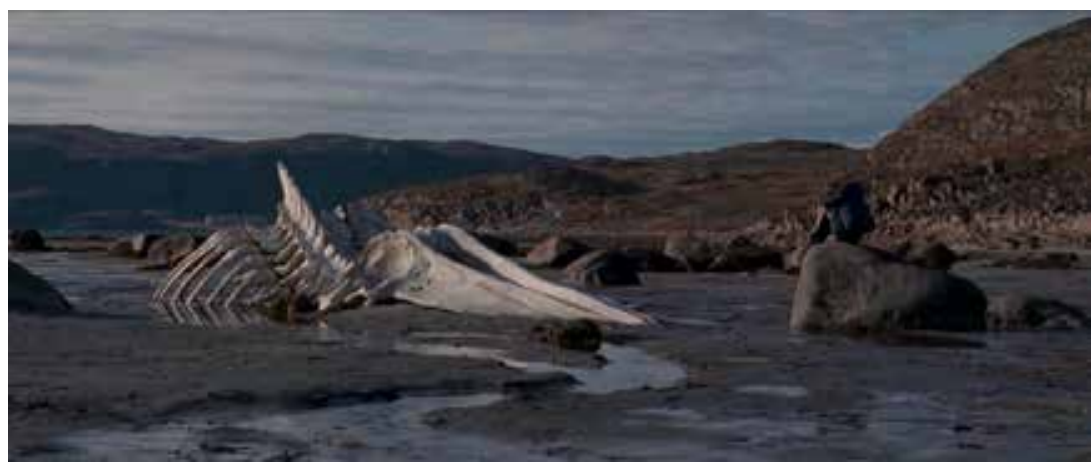

Figure 10.1 Leviathan: the small figure of Roma sits opposite the enormous whale carcass.

expansive seascape that made it a coveted spot for the corrupt Major, Vadim, resulting in Nikolai's relentless persecution and final incarceration, with his house being razed to ground and the land appropriated by the church. Elsewhere, in the film, shots of spectacular landscapes are interspersed to reassert their crushing power over the minute human beings photographed against them, as in the scene in which Nikolai's current wife, Lylia, looks at the immense sea, from the top of a rock, and spots a whale breaching; Lylia's dead body will be subsequently retrieved from the sea as a result of a mysterious murder or suicide. Shortly before that, a majestic skeleton of a dead whale stranded on the beach had forecast the tragedy, in another spectacular series of shots where the small figure of Roma (Lylia's rebellious stepson) sits in distress opposite the enormous carcass (Figure 10.1). The carcass itself is, however, the proof of human interference in what should have been a 'natural' landscape, as it is the result of a careful reconstruction for the film.

Whale, sea and rocks here present their own tacit and mysterious narrative, based on spectacle and duration, flirting with the sublime, whilst alluding to the biblical legend of the destructive sea monster Leviathan, announced in the film's title. This, in turn, resonates with the prominence of religion in the film in the figure of a bishop enmeshed in the corruption network led by mayor Vadim, and it is the church, erected for him by the mayor, that ends up dominating the landscape. This example demonstrates how the landscape in a film can come in and out of the narrative thread, adding religious, mythic and legendary overtones to the story and overflowing the fictional frame to connect with historical and political reality. In the next section, I shall examine how it can also constitute a world in its own right. 


\section{Landscape, Worldhood and Otherworldly Invaders}

As Harper and Rayner (2010: 16) point out, 'Landscape involves isolation of a certain spatial extent and a certain temporal length'. 'Isolation' in its strongest sense is indeed key to the settings in the films in question here, consisting of remote areas whose insular condition allows for the issues in focus to unravel undisturbed, with enhanced clarity and poignancy. As Harper and Rayner (16) go on to say:

all notions of landscape are produced by human interpretation which, simply due to human physiology or due to political or cultural bias, is selective. Subsequent aesthetic treatments of landscape, whether in painting, photography or film, involve further selection, interpretation and omission, whether by an individual or group [...] Like a map, the cinematic landscape is the imposition of order on the elements of landscape, collapsing the distinction between the found and the constructed.

We have seen above, in the example of Leviathan, how the found and the constructed are combined, most impressively in the constructed whale skeleton, an artwork installation on a natural rocky beach.

'Ordering' and 'arranging', in turn, pertain to the very concept of landscape and are at the heart of Rancière's (2020) recent take on the subject as an extension of his theory of the aesthetic regime of art, whose appearance he dates back to the early eighteenth century. Rancière's point of departure, in this respect, is - as for most philosophers - Kant and the moment he included gardening into his classification of the fine arts, describing it as 'the beautiful arrangement of natural products' (Rancière 2020:13). As a radical interference into nature, gardening, for Rancière, has the inevitable consequence of imposing limits to it, as Kant (1914: 2nd book, $§ 23$ ) had also observed when distinguishing the beautiful from the sublime, in his Critique ofJudgement:

The Beautiful in nature is connected with the form of the object, which consists in having boundaries. The Sublime, on the other hand, is to be found in a formless object, so far as in it or by occasion of it boundlessness is represented, and yet its totality is also present to thought.

Beauty is no doubt a criterion for the selection of the landscapes here, whose compositions are primarily meant to elicit aesthetic pleasure, if one just thinks about the exquisite shots of the desert in Birds of Passage, Timbuktu and The Story of the Weeping Camel, or the rocky formations in Winter Sleep 
and Leviathan. Beyond their formal beauty, i.e. the selective containment and ordering of their elements, a sense of infinity and formlessness is preserved which Kant associates with the sublime. For Kant, nature is sublime in those phenomena whose comprehension surpasses any stretch of human imagination (§ 26). He names among those phenomena (§ 27):

Bold, overhanging, and as it were threatening, rocks; clouds piled up in the sky, moving with lightning flashes and thunder peals; volcanoes in all their violence of destruction; hurricanes with their track of devastation; the boundless ocean in a state of tumult; the lofty waterfall of a mighty river, and such like; these exhibit our faculty of resistance as insignificantly small in comparison with their might.

Rocks and ocean such as those described by Kant are a prominent feature in Leviathan, as are the deserts and rocky peaks in all the other films, along with the recurrence of the compositional vanishing point, which, as spectacle, claim their own duration. When part of the spectacle, human beings are shown as minute in relation to the boundless landscape. Lylia and Roma, in Leviathan, are exemplary diminutive figures in relation to the endless ocean and the whale carcass; in Winter Sleep, the protagonist Aydın is first introduced to us as an insignificant figure against the magnitude of the surrounding rocks, and so are the tourists lodging in his hotel who form a thin winding line on top of the rocks (Figures 10.2, 10.3). In Birds of Passage, the vanishing point is stressed as such, by means of the parallel tracks of a disused railway on the desert, an artificial addition to the natural landscape apparently aimed at producing, precisely, a vanishing point, on which the ancestral matriarch, a grandmother raised from the dead in her granddaughter Zaida's dream, marches towards the infinite horizon (Figure 10.4). 'The sertão is everywhere' and 'the sertão is the size of the world', states the narrator of Guimarães Rosa's famous novel, The Devil to Pay in the Backlands, and indeed in Bacurau the boundless sertão is simply what there is, the entire world.

Thus, if processes of selection are necessarily carried out for the formation of landscapes, and further changes are introduced to them to suit the associated fictional narrative, landscapes in these films strongly contribute to the sense of totality or 'worldhood' as Yacavone (2014) has named it. Building upon and modifying what has traditionally been called diegetic and nondiegetic worlds, Yacavone distinguishes between the world 'in' a cinematic work, which is fundamentally representational and denotative, and the world 'of' it, which is connotative and presentational, including 

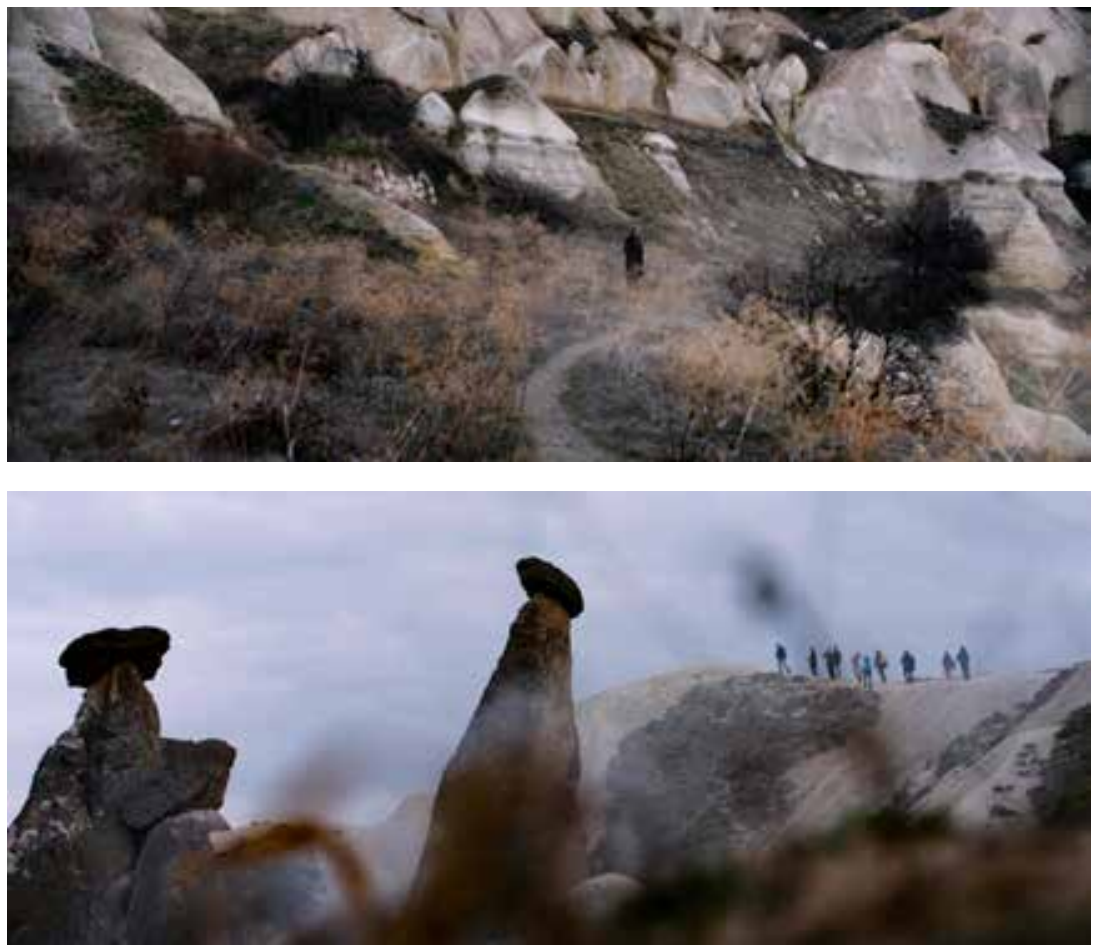

Figures 10.2, 10.3 In Winter Sleep, Aydın is first introduced as an insignificant figure against the magnitude of the surrounding rocks, and so are the tourists who form a thin winding line on top of the rocks.

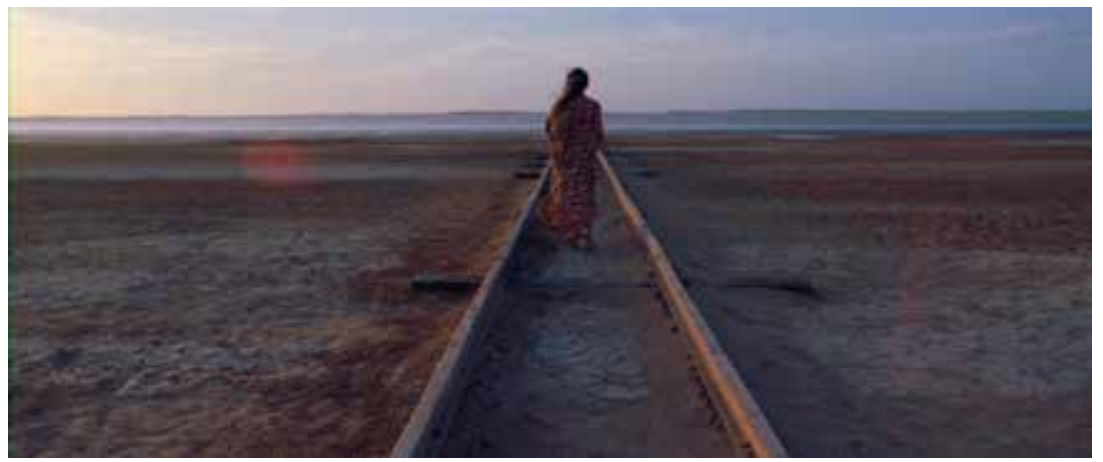

Figure 10.4 In Birds of Passage, the ancestral matriarch, raised from the dead, marches towards the infinite horizon. 


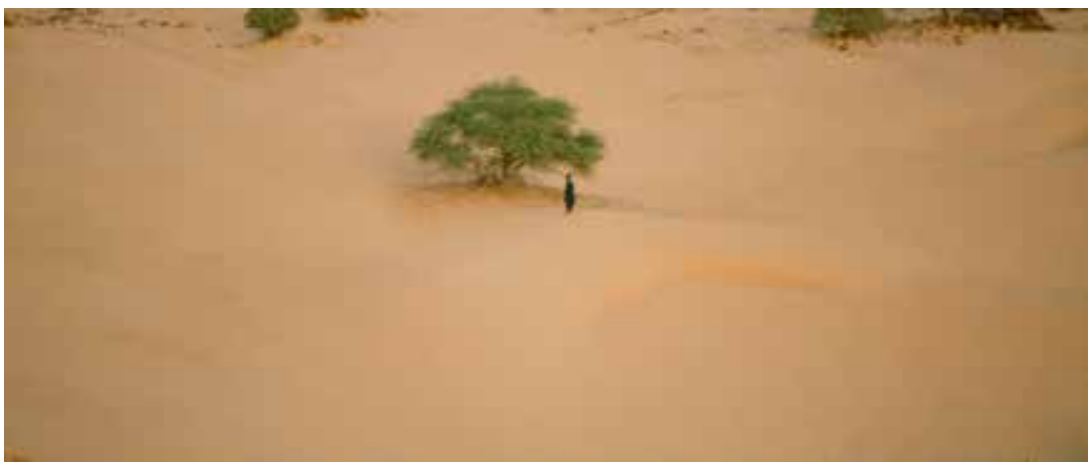

Figure 10.5 Timbuktu: the orphaned adolescent Toya is a minute figure in the endless desert.

and enclosing the former. This connotative property, overflowing the representational world of fiction, could be attributed to the autonomous landscapes in the case studies here, in that they open up a path for fictional and objective reality to communicate. Let us have a look at how landscapes can indeed function as an all-enfolding more-than-fictional, i.e. cultural and historical world.

In Timbuktu, landscape is associated with life on it from the opening images, showing a gazelle running on the sand, its colour barely distinguished from the light-brown Sahel soil. Gunshots are heard and the next shots show a pick-up truck full of militia men firing at the gazelle. What comes next are, first, wooden masks piled up in the sand and being destroyed by gunshots fired off-frame, then wooden sculptures of men, women and children, some playing instruments, being equally shot at and turning to dust. As the film progresses, a Tuareg musician family is likewise destroyed, father Kidane and mother Satima killed and the orphaned adolescent daughter Toya turned into a minute figure running aimlessly in the endless desert (Figure 10.5). Thus landscape here is, from the outset, defined as origin and final destination of all life and culture, its connotative resonances extending beyond fiction to the radical Islamist group Ansar Dine who in 2012 took hold of the sacred city of Timbuktu and the surrounding area, destroying many of their mausolea, tombs and historical documents. The colour pattern and figurations in the film produce a near-total identity between landscape, city, animals and people, including the moment in which Ansar Dine leader Abdelkerim, in his unsatisfied lust for Satima, trims the bush between two dunes with gunshots, the dunes appearing to him (and to the spectator) as a naked female body, and the bush, her pubic hair (Figure 10.6). Any expert viewer will infer the postproduction effects that made these images possible, though their factual and historical connotations remain intact. 


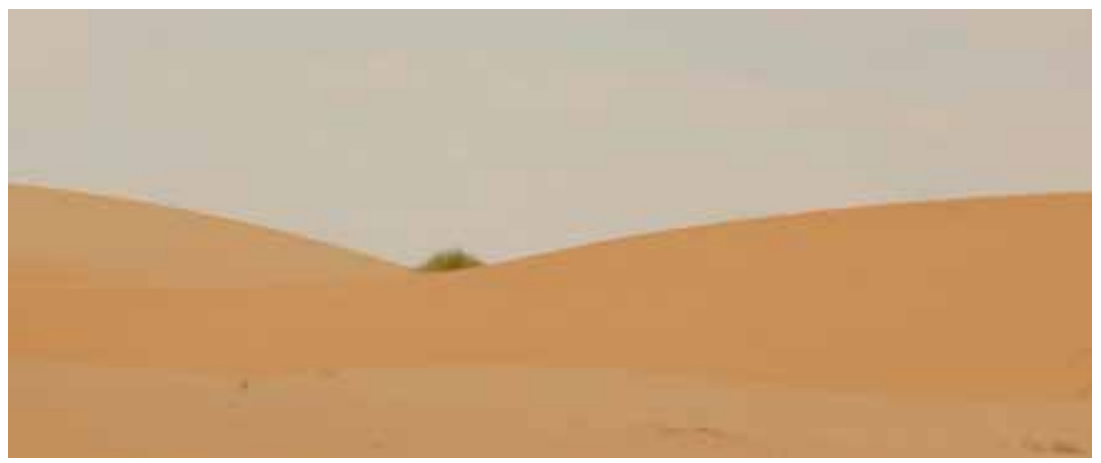

Figure 10.6 Timbuktu: Abdelkerim, in his unsatisfied lust for Satima, trims the bush between two dunes with gunshots, the dunes appearing to him as a naked female body.

This gun attack on the landscape as political act curiously chimes, albeit with a reverse meaning, with Leviathan, in which an outing among friends to a beauty spot away from Pribrezhny, gives them the opportunity not only to drown in vodka but also to exercise their fingers on target shooting with an impressive set of weaponry, including machine guns, using as targets empty bottles but also portraits of former leaders of the country.

In Bacurau, the worldhood of the sertão is signified on different levels. First as a forlorn, boundless scrubland, where the population of a tiny village, called Bacurau (or nighthawk), is starved of water by a scheming, self-serving populist mayor, Tony Jr, the 'junior' in his name indicating a lineage of reckless rulers. The village is yet another world in itself, collecting as it does all minorities of race (white, black, indigenous people), sex (gays, lesbians, transgenders and prostitutes) and social bandits, all of whom are unsuspectingly sold by the mayor to a group of invaders from the US, Europe and São Paulo (a wealthier state in the southeast of the country), practising human hunting for pleasure on the land. This kind of refugee camp, deleted from Google maps by the foreign hunters, is in fact constructed on what had been a quilombo, or one of the many settlements established by fugitive African slaves during colonial times, between the seventeenth and nineteenth centuries. Though quilombo is not named as such in the film, an azimuth mark on the dirt ground, with the words 'protected by law, please do not remove', leads to the discovery of an underground bunker, testifying to this ancient history. This is where the population hides from the hunters' attack, and where the last of Bacurau's enemies will be buried alive.

If, in Timbuktu, the anthropomorphising of the land turns it into the maternal womb and final grave of all beings, in Bacurau the burial of an old matriarch, Carmelita, the genetrix of most of the local population, gives 
origin to the story of the land itself. In this parodic sci-fi, whose future is a winding back to a time when humans went about naked and talked to plants, matriarchy is a haven of political correctness and general tolerance at war with a corrupt politician and foreign afficionados of gun culture. Given its connotations of political facts in present-day Brazil and of the current governmental support to gun violence in the United States, the film has been celebrated as a political manifesto. More encompassing and generally relevant, however, is the real history embedded in that land, a history of slavery and of social banditry, involving not only Pernambuco but all neighbouring northeastern states and enshrined in Bacurau's local museum, where pictures, documents and weapons from the cangaceiros, or social bandits of the early twentieth century, are stained with the blood of the current fighters.

Mixture of fact, fiction and cinephilic citations, Bacurau resonates with Birds of Passage, where the Wayúu are also governed by a matriarch, Úrsula Pushaina, redolent, as indicated by Cristina Gallego herself, of Úrsula Iguarán, the matriarch of Gabriel García Márquez's foundational magicalrealist novel, One Hundred Years of Solitude. Both films are structured in the form of oral storytelling by means of intradiegetic figures of bard singers, the bard in Bacurau being reminiscent of the cordel storyteller in Glauber Rocha's Cinema Novo landmark Black God, White Devil (Deus e o diabo na terra do sol, 1964). Birds of Passages is even divided into 'five songs': Wild Grass, The Graves, Prosperity, The War and Limbo. Drawing on oral tales of origin and death, these songs in turn open up for the retelling of the so-called 'Bonanza Marimbera', or the period between the 196os and 1980s when indigenous populations in Colombia took the lead in drug trafficking, before it became the all-pervading belligerent business that continues to ravage the country up to today.

It has been said about Birds of Passage that:

The colourful and rich indigenous culture shines in impacting images that move away from the western optic of commercial cinema. Nature, animals, skies, the soil, plants, everything shines and reverberates. Even death gains the sublime appearance of a bird and is perfectly attuned to the feeling of such a unique and precious film. (Chang 2019)

Beauty, nature and the sublime are certainly called for in this expansive landscape where humans merge with animals and these with the earth. As in Timbuktu, anthropomorphising is part of the world-making of the film and enacted from the beginning by the yonna courtship dance. Having emerged 


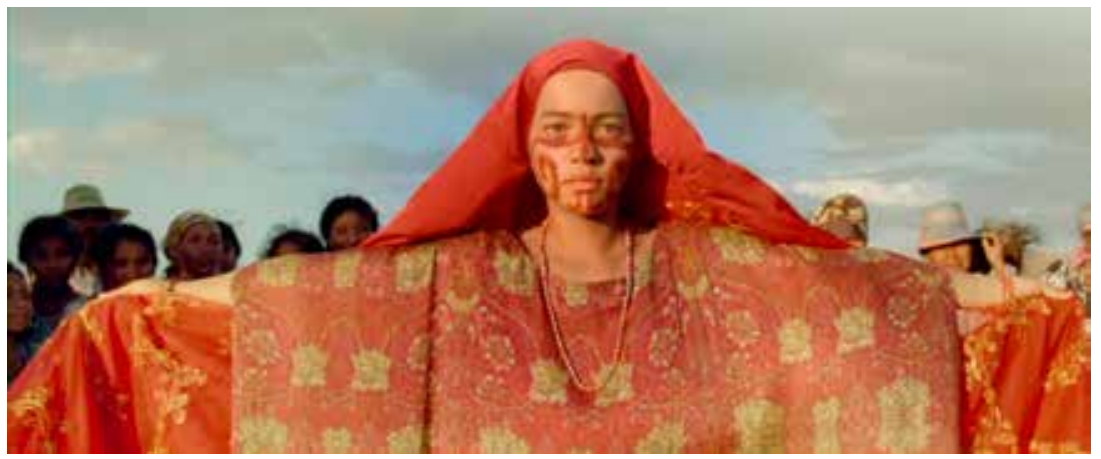

Figure 10.7 Birds of Passage: Zaida performs the yonna courtship dance.

from her yearlong confinement as she reaches puberty, Zaida performs this dance to her village folks, donning a shiny red silk cape that she opens up on her stretched arms in the form of a giant bird floating in the wind, while moving forward with small steps to the beat of a drum (Figure 10.7). A suitor puts himself forward, the dazzling Rapayet, who marches backwards as she charges him, and survives the challenge without falling over. Still, he has to amass a hefty dowry of 30 goats, 20 cows and five precious necklaces for his marriage proposal to be accepted, and to that end initiates a marijuana traffic, first to quench the craving of hippies working as members of the American anti-communist Peace Corps, then selling wholesale to America via air traffic.

The ensuing violence that decimates the Wayúu clan, after some years of power and prosperity, is announced by birds which represent yoluja, or dead spirits, and appear in Birds of Passage as the living sign of the reality overflowing the fictional world. The marvellous but sinister blood-red iishcoo, or cardinal guajiro, is one of the unique specimens of that habitat, together with a wading bird which circles those about to die or already dead both in the characters' dreams and in their fictional reality. Beauty as bad omen is in fact the film's leitmotiv, one that chimes with the realisation of the impossibility of the inaccessible island of Utopia. In both Birds of Passage and in Bacurau, the perfectly integrated worldhood of fiction is torn apart by otherworldly invaders, bringing them, so to say, back to Earth and to the political issues of our time. The 'back-to-Earth' theme is in fact literally announced as such at the very beginning of Bacurau, which starts with an image of the Earth from outer space, including an orbiting satellite and other space detritus, before plunging into what is referred to as the Pernambucan sertão. The music, meanwhile, is 'Não identificado' (non-identified), by Caetano Veloso, about love as a UFO, and indeed the 
otherworldly invaders will be heralded in Bacurau by a drone in the shape of a flying saucer.

Thus, landscape in these films, selected and organised as it must be in order to exist, points at and gives evidence of the vulnerability and finitude of its worldhood, but also the indexical historic and political reality within and beyond it.

\section{The Reality of the Cave}

Theorising cinema in connection with the world goes back a long way and continues to attract strong research interest today. Tiago de Luca (2018: 19) identifies a 'ubiquitous trope' in world cinema, in the last two decades, of depicting 'not a world, but the world'. De Luca goes on to connect this trend, derived from the acceleration of globalisation in the digital age, to the 'global imaginaries' that propelled the very emergence of cinema in the nineteenth century. According to this vision, therefore, technology is what impels cinema to represent, or even stand for, the entire world.

Both the questions of realism and totality, as enabled by the technology of cinema, send us back to Bazin and his pioneering article 'The Myth of Total Cinema' (1967). As Hassan (2017:39) has persuasively argued, for Bazin 'the time of cinema was quite simply the time of the drive to totality, amidst an epochal experience of modernity as technologically driven dispersal and democratization of history'. In formulating his concept of 'total cinema', Bazin was most certainly inspired by science-fiction writer René Barjavel, whose futuristic book-length essay Cinéma total: essai sur les forms futures du cinéma, written in 1944, has only recently returned to the debate thanks to the translation and exegesis of his work by Alfio Leotta (2018). Barjavel's prophetic book imagined a time when technology would enable cinema, in its relentless search for realism, to 'offer characters in full relief, in full colour, and even perhaps whose perfume we can detect; a time when these characters will be freed from the screens and the darkness of the film theatres to step out into the city streets and the private quarters of their audiences' (apud Leotta 2018: 375). 3D, 4D, augmented reality, expanded cinema and even the liberation of film from the theatrical auditorium and into other spaces including the streets and private homes were prefigured in his book. Though he most certainly read Barjavel's book before writing his own essay, Bazin, however, refrains from making any mentions of it. One possible explanation for this advanced by Leotta $(373,380)$ is Barjavel's dubious political credentials, as during the Second World War 'he was 
associated with collaborationist intellectuals and publishers, and was himself suspected of collaborating with the Nazi invaders'. However, both Barjavel and Bazin resort to nineteenth-century pre-cinematic technical experiments to explain the human ambition to obtain a complete mimesis of the world, and while Barjavel declares that 'cinema does not yet exist', Bazin exclaims that 'cinema has not yet been invented!' (Leotta 2018: 375). Whatever the case, total cinema as prophesised by Barjavel and formulated as a 'myth' by Bazin continues to be 'a perfect illusion of the outside world in sound, color, and relief' (Bazin 1967: 20), rather than the outside world itself. Tom Gunning (2011: 122) notes that 'The Myth of Total Cinema' 'not only challenges traditional (and even subsequent) historiography but also highlights the fault line in Bazin's realism: its relation to illusion and deceit'. Gunning goes on to say that 'it is striking that nothing in "The Myth of Total Cinema" seems dependent on indexicality or even necessarily on photography', and my explanation of this is simply that here Bazin is not referring to realism as mode of production, but as mode of reception. As such, therefore, total cinema is simply the more advanced form of standard cinema as experienced by means of what Baudry (1986) famously defined as the 'basic cinematographic apparatus', involving the projector, the dark room and the collective audience, whose function is to produce an 'impression of reality', rather than reality itself.

Illusion is therefore at the base of all thought leading to the concept of 'total cinema'. However, illusion may not be as divorced from the phenomenological real as it may seem. Indeed, Baudry's theorising on the ideological effects of the basic cinematographic apparatus is aimed at identifying the moment at which, amidst 'copy, simulacrum, and even simulacrum of simulacrum', between the 'impression of the real' and 'more-than-the-real', truth finally occurs (1986: 299). To that end he resorts, in the first place, to the allegory of the cave, as found in Plato's Republic (n/d), in the form of a conversation between Socrates and Plato's brother, Glaucon. As already explained in Chapter 2, the allegory concerns prisoners chained to the wall of a cave who take for real living beings the magnified shadows of artefacts projected by a firelight behind them on a wall opposite them; the sounds produced by those manipulating the artefacts are likewise believed to emanate from the shadows. Therefore, for Baudry, Plato's allegory of the cave constituted the perfect prediction in the smallest detail of the workings of cinema. Now for Plato, of course, this was a thoroughly undesirable situation, and in this passage of Republic, Socrates leads Glaucon to understand the advantages of releasing the prisoners from their chains and exposing them, first, to the reality inside the cave and then to the sunlight outside it. As a 
result, they can finally recognise the real world beyond the shadows in the cave and the benefits of enlightenment, that is, education. It is however a long process of learning involving pain and disappointment. The prisoners would initially be blinded by the glare of the fire inside the cave, then of the sun outside and, on occasion, wish they were back in their dark cave and looking at their familiar shadows.

In order to pinpoint where 'truth' actually lies, Baudry then resorts to Freud's concept of the unconscious and his call for the conscious mind to return to that obscure place within the 'mental apparatus', rather than liberating itself from it and searching for the light. Here, Baudry points to a similarity in Plato's and Freud's lines of thought in that both encourage their subjects to look at the apparatus and identify its workings in order to recognise the reality of the trick in the first place. What most fascinates Baudry about Freud's definition of the 'mental apparatus' is again, as in Plato, its similarity to cinema. He demonstrates, in fact, that a kind of cinematic apparatus was embedded in Freud's oeuvre as a whole, from his early Interpretation of Dreams, written in 1899, to his late An Outline of Psychoanalysis, written 41 years later, and cites the following passage from it:

I [Freud] propose simply to follow the suggestion that we should picture the instrument which carries out our mental functions as resembling a compound microscope or a photographic apparatus, or something of the kind. On that basis, psychical locality will correspond to a point inside the apparatus at which one of the preliminary stages of an image comes into being. In the microscope and telescope, as we know, these occur in part at ideal points, regions in which no tangible component to the apparatus is situated. I see no necessity to apologize for the imperfections of this or of any similar imagery. (apud Baudry 1986: 300)

Considering that Baudry extends the definition of the basic cinematographic apparatus from the recording of images to the moment of its reproduction, the middle point in the microscope or telescope in which an image emerges in the unconscious, according to Freud, could be compared with the moment of truth of a film, though for Baudry this would be purely the moment of the revelation of the reality of the apparatus itself. But could this not also be the moment where evidence of reality, in the form of images and sounds, is collected, a revelatory moment whose truth shines through the entire piece of work, despite all artifice resorted to in a film at both production and postproduction stages? 
This question gives me the opportunity for a reflection on Winter Sleep, in which the allegory of the cave materialises in two literal caves, serving respectively for a character to abscond from reality and for reality itself to abscond. With clear affiliation to Russian realist literature (see Mathew 2019 in this respect), the film is a self-reflexive meditation on the role of the artist when faced with social issues in the objective world. The central character is Aydın (meaning 'intellectual' in Turkish), a retired actor turned writer, who contributes a regular column to a local newspaper while compiling data for his future magnum opus on the history of Turkish theatre. He is the owner of a hotel, suggestively called Othello, at the top of one of the rocky peaks in Cappadocia where he lives with his much younger wife, Nihal, and divorced sister, Necla. He is also the wealthy heir of many properties in the region.

Aydin works in a study adjacent to his hotel, a repurposed cave inside the top of a rock, from where his eyes command the portentous landscape outside. There he spends most of his time immersed in his literary fantasy, which he occasionally shares with visitors, including his semi-estranged wife and disgruntled sister, whose favourite pastime is to accuse him of 'lack of realism' and inability to see beyond his acting mask. Miles below him, in another cave at the bottom of the mountains, lives the Hodja family, one of his tenants, consisting of unemployed miner and ex-prisoner İsmail, his mother, wife Levda, pre-teen son İlyas and brother Hamdi, an Imam. The Hodjas are going through extreme financial difficulties, living out of the imam's meagre resources and standing in long arrears with the rent. Aydın wouldn't have taken any notice of this family, were it not for young İlyas throwing a stone and breaking the window of his pick-up truck, as he drives on an errand with his chauffeur Hidayet. Hidayet runs after the boy, picks him up just as he accidentally falls into a freezing stream and brings him back to the family. Aydin watches from a distance as Hidayet returns İlyas to his resentful father and is horrified with all the scrap metal and rubbish strewn on what should have been the front garden of the house. This offence to Aydın's aesthetic sense confirms the assessment contained in one of his most popular press articles, 'Urban Ugliness in Anatolia'. This is however just the spilling out of the ugly reality of the Hodjas' cave house that Aydın refuses to approach.

One day, Aydın's wife, Nihal, visits the Hodjas in secret, believing that her husband has gone to Istanbul. She brings with her a great sum of money that Aydın had contributed, rather begrudgingly, to her charity work. Nihal's intention is to donate the money to the needy family, seemingly without realising the enormity of her offer, which could even buy a new house for them. She also has no idea of the outrage her entering the house, clearly against the will of the much-obliging imam, can cause. Her beauty, her loose 
long hair in a pious Muslim home, her independence from her husband who the imam expected to be with her, her wealth emanating from every single detail in her attire and attitude, all is a silent act of aggression in a house which has been stripped of its fridge and TV set by the police, on behalf of Aydın's lawyers. Nihal also has to confront Ilyas, suffering from pneumonia after his fall in the freezing stream, who does his homework with a blanket over his shoulders. What she imagined to be a magnanimous gesture is received with indignation by İsmail, a regular drunk and troublemaker, who, to Nihal's horror, throws the money into the flames of the fireplace. The falling of the masks here with the sudden revelation of the unbridgeable gulf between the classes is all the more effective for taking place in the womb-like cave excavated in the rock, the unappealing interior of the dazzling landscape outside, and as effective in the fictional plot as it is in the indexical reality of a vertical society engraved in the natural design of the rocky landscape. The image of the money burning in the fireplace is one that lasts on the screen, resonating with the glaring effect of the fire on the prisoners in Plato's cave as they come to apprehend the treacherous workings of the apparatus of fiction and the truth about their own unconsciousness.

\section{The Reality of the Myth}

It is now time to return to Bazin and consider the ways in which he sought to connect total cinema and realism, before delving into my last filmic case study, The Story of the Weeping Camel. At the origin of Bazin's article, 'The Myth of Total Cinema' (1967: 21), is the publication of Georges Sadoul's monumental history of cinema, Histoire génerale du cinéma: L'Invention du cinéma. What most intrigues Bazin in this book is its description of the invention of cinema, led by obsessive handymen, rather than men of science. In this, and in defiance of Sadoul's staunch Marxist convictions that inform his book, Bazin explains this as a reversal of the Marxist order of causality going from the economic infrastructure to the ideological superstructure, concluding instead that the technical invention of cinema comes 'second in importance to the preconceived ideas of the inventors' (Bazin 1967: 17). He says:

The cinema is an idealistic phenomenon. The concept men had of it existed so to speak fully armed in their minds, as if in some platonic heaven, and what strikes us most of all is the obstinate resistance of matter to ideas rather than of any help offered by techniques to the imagination of the researchers. (17) 
Despite this reversal, Bazin's view continues to be evolutionist, in line with his belief that all technical innovations in the audiovisual media would ultimately benefit realism. Thus, the silent and the sound film were 'stages of a technical development that little by little made a reality out of the original "myth", this myth being 'an integral realism, a recreation of the world in its own image' (21). However, as Angela Dalle Vacche (2020:59-60) reminds us, even if he 'pays close attention to technical innovations, for Bazin the person behind the camera and the world in front of it count much more than mechanical virtuosity displaying itself for its own sake'. This is why technological progress will do nothing but take us closer to where it all started: the moment when cinema had not yet been technically invented (Bazin 1967:21). What Bazin offers by coming full circle, I wish to claim, is the encounter with reality at the opposite end of the illusionist reception, that is, at the point of the film's production. Let us now turn to my final case study in order to explain how this might be confirmed in practice.

The Story of the Weeping Camel was scripted and directed by Byambasuren Davaa and Luigi Falorni, who were at the time film students in the Hochschüle für Fernsehen und Film, or the School of Television and Film (HFF) in Munich, venturing for the first time into the feature-length format. Crew, cast and equipment were thus restricted to the bare minimum to fit their stringent budget, with just the essential footage of $16 \mathrm{~mm}$ celluloid stock, allowing for hardly any reshoots or waste. Hence Davaa and Falorni's colossal achievement, rather than owing to sophisticated techniques, is entirely thanks to their 'idea', which finally bent the 'obstinate resistance of matter', to use Bazin's vocabulary. The original story came from Davaa's memories of an ancient legend, described in a short educational film she had watched as a child in Ulaanbaatar, the capital of Mongolia, about the hoos ritual. This involves playing the murin khuur, a kind of two-stringed violin, that brings a mother camel to tears and makes her reconcile with the offspring she initially rejects. As Farloni explains (Winter 2004), the film was entirely scripted in Munich, before the crew embarked on their 23-day expedition in the desert during the camel birthing season in the month of March, in order to verify the efficacy of the ritual. By a stroke of luck, they found an intact family of four generations, living in three adjacent gers (Mongolian tents), owners of 300 sheep and goats and 60 camels, and, in their company, were able to witness the birth of some 20 camels. At long last, one colt, a rare albino, was born after a prolonged labour and rejected by his mother. Even more astonishingly, the mother camel eventually reconciled with her colt after undergoing the hoos ritual, an indispensable development for the film to exist. 


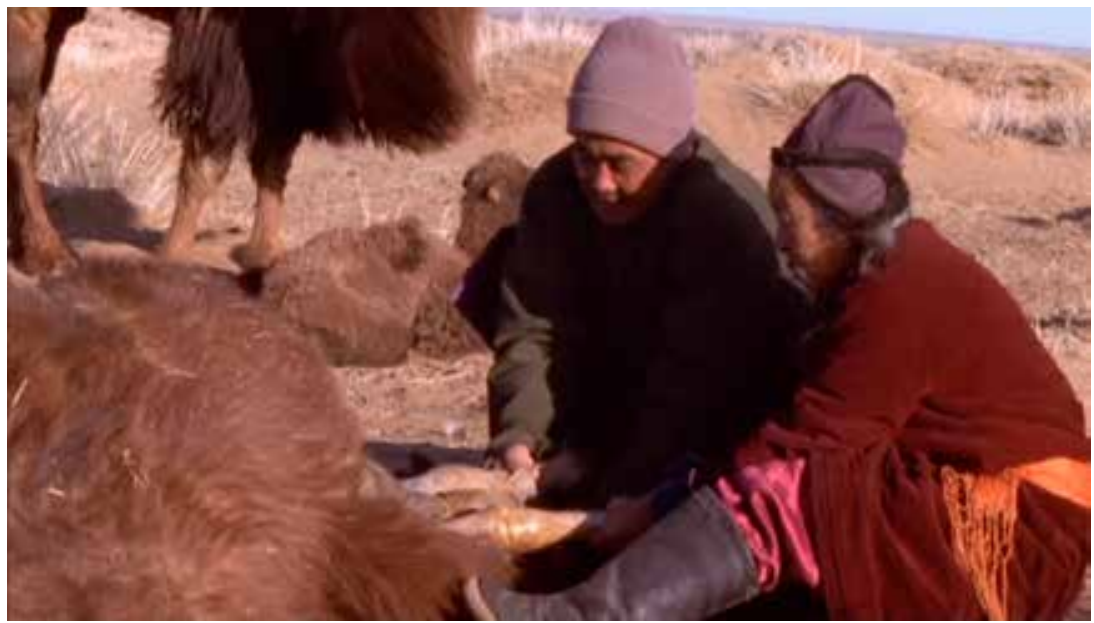

Figure 10.8 The Story of the Weeping Camel: the mother camel's delivery of her colt is finally completed with the help of several members of the protagonist family.

That Davaa and Falorni would succeed so thoroughly in their endeavour, by obtaining full real-life evidence of the legend, is nothing short of a miracle. In fact, the entire film is a collection of miracles, not least the birth and survival of the albino colt, after the camel's two days of excruciating labour, during which the colt's front legs and head remained stuck outside her for hours. The delivery is finally completed with the help of several members of the family (Figure 10.8), but after so much pain the mother refuses to welcome and breast-feed the baby. This unique event of birth is only comparable to death in its irrefutable reality that can never be represented, i.e. repeated, but only re-presented onscreen. This combines with the animals' behaviour which, though scripted, happened entirely spontaneously in front of the astounded crew. Falorni talks about the 'choreography' between the mother camel and her abandoned colt, who desperately approaches her for milk and is repeatedly kicked away (Winter 2004) in the vast desert landscape. The camera was able to capture all this by mere chance, given that, as Falorni discovered, 'it is impossible to direct a camel' (Winter 2004).

Cut and reduced though it may be, this reality is, nonetheless, cosmogonic. In her reading of the film in light of ecocriticism and consilience, St Ours (2011: 397) highlights the 'interdependence of a nomadic people and their domesticated animals within the natural environment upon which both rely for survival'. Indeed, the universe the film confronts us with is composed of inextricably connected elements where the undulating mountains in the horizon of the vast desert mirror the shape of the humps of camels in the foreground (Figure 10.9). Similarly, the sheep with their lambs and camels 


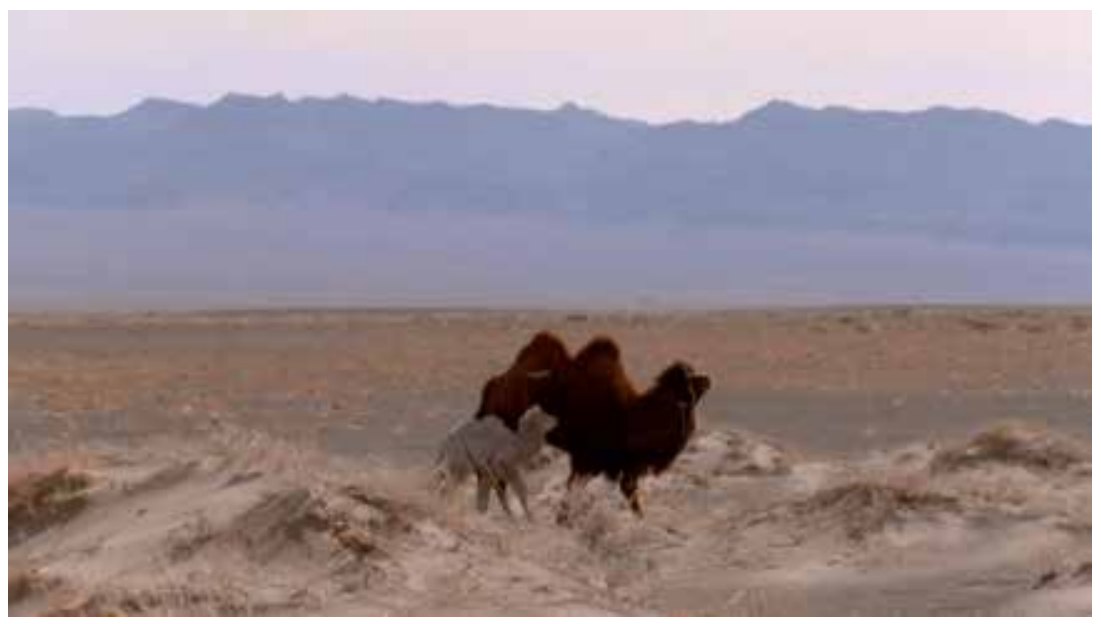

Figure 10.9 The Story of the Weeping Camel: the undulating mountains in the horizon of the vast desert mirror the shape of the humps of camels in the foreground.

with their fillies and colts entertain mother-child relations identical to those of humans. They are even interchangeable, when a mother, Ogdoo, after feeding her own child, Guntee, feeds the abandoned colt with a bullhorn full of milk. As much as the baby camel, tied to a post, wails in seeing his mother retreat into the desert, baby Guntee screams when she is tied to the leg of a bench in her great-grandmother's ger when Ogdoo goes out to work. At the end of the film, before the rolling credits, all characters are introduced to the viewers with medium close-ups and their respective names, in the manner of a slideshow, including Ingen Temee and Botok, the mother camel and her albino colt, who close the presentation in a hilarious frontal shot (Figure 10.10). St Ours (2011) declines to address this procedure in terms of anthropomorphism or anthropocentrism, which are unwelcome terms in ecocriticism. Indeed, what is at play here is much rather a perfect totality of equivalent and complementary elements.

All of this is constructed, evidently, by the expert manipulation of script, camera and editing, which manages to present four generations of a single family living in perfect harmony, all healthy and active, without riffs, jealousy or malevolence, equitably engaged in the house and land work, running the mill, cooking, weaving, breeding, shearing the animals and warmly entertaining occasional guests. Their benevolence towards the animals and their environment is boundless, to the point of this fundamentally carnivore society never once being shown eating meat, but only their milk products and accompanying sweets. Likewise, their ritualistic habits are shared with equally good-willed neighbouring people in collective ceremonies in honour 


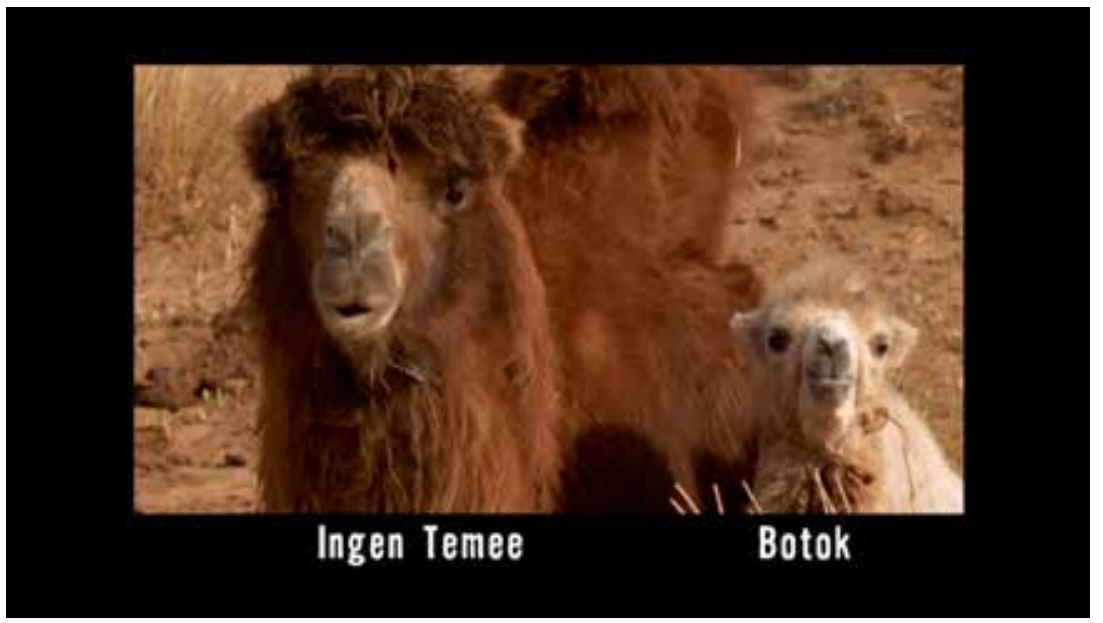

Figure 10.10 The Story of the Weeping Camel: Ingen Temee and Botok are presented at the end as members of the cast, in a hilarious frontal shot.

of nature and its protective spirits. In short, landscape and its human and non-human animal societies live here in utopian peace and harmony similar to that found in Bacurau, though without any of the violent disruption and carnage that affect the latter. In all this, selection, composition and, not least, manipulation become evident.

As much as with the other cases examined here, this harmony is entirely dependent on idealistic isolation, on the inaccessible quality of that spot in the vast desert, together with its sparse population. This is how their worldhood is constructed and emphasised at regular intervals with extended shots of the boundless desert, which claims a spectacular time of its own. The interdependence of isolation and harmony is, indeed, stressed by the film producer, Tobias Sieber (apud Winter 2004), who appropriately resorts to the metaphor of a boat in the sea to explain this situation:

We were at the end of nowhere. It was a four-hour drive from the nearest city. We didn't have a shower. It was a bit like being on a small boat - we were surrounded by endless space but had to pack together in one tiny little place, so it was important that everyone got along.

There is, however, an important suggestion of the encroachment of modernity which places this cosmic harmony under threat, though this is also presented as a natural development. Little Ugna insists on accompanying his older brother Dude on a trip to the nearest urban settlement, Aimak, 50 kilometres away, on camelback, in order to fetch a player of murin khuur 
to perform the hoos ritual. He is so small that he needs to be helped by an adult onto the back of a sitting camel, and yet he demonstrates himself to be an excellent and self-confident rider, in a film where any stunts would be unimaginable. As a representative of the young generation, Ugna is also the one most attracted to the novelties of $\mathrm{TV}$, computer games and ice-cream he becomes acquainted with in Aimak, and it is in his honour that the film ends with the installation of a solar panel and a satellite dish on their ger, to power a new TV set inside, signalling perhaps the approaching end of their harmonic lifestyle.

The Story of the Weeping Camel is an oral as much as aural tale. It starts, like Birds of Passage, with an elderly storyteller establishing the narrative grounds by retelling the legend of the camel who lent its antlers to a deer and is now forever contemplating the horizon, waiting for the deer to return with his antlers. More than the tale itself, it is the great grandfather's voice and pleasant-sounding Mongolian language that is the focus. Most strikingly, there is perfect harmony between the sound of the wind, the wailing camels and the human singing and playing, which makes the most part of the soundtrack in this rather laconic film. It is also sound that brings the film to its climax. We had already been given ample demonstration of the soothing effect of human sounds and singing, through the family members making an effective 'aah' sound to summon up and calm down the camels, and Ogdoo's beautiful lullaby that sends Guntee to sleep. The onomatopoeic hoos ritual then gives us a full display of orchestral harmony between nature, animals and humans.

It starts with the grandfather tying the khadag (a blue silk scarf used in sacred ceremonies) (St Ours 2004: 400) to the murin khuur and hanging it on the mother camel's front hump. As the wind makes the murin khuur's strings vibrate, the camel, until now very agitated, suddenly calms down and her fearful grunts turn into a more continuous and low pitch mooing in tune with the murin khuur's vibrations. These sounds, together with some dogs barking and the little colt's wailing in the background, make a strangely attuned ensemble. Ogdoo then starts to sing the hoos acapella, while stroking the camel's hair on the side of her neck. After a while the violin joins in, at which point we see alternate shots and reverse shots of her hands stroking the camel's hair and the violinist's bow running over the horsehair strings. In the meantime, the entire family and all camels around look at the scene in complete silence, as if hypnotised. The colt is finally brought close to his mother and gradually dares to approach her teats and start suckling. The camera then offers close-ups of the tears that well up to the mother's eyes and fly in the wind. The whole process, extending for 
around six hours in reality, is shown in the film in c. 10 minutes of edited stock. However, each of the takes and accompanying sounds burst with irrefutable reality, one that could not possibly be fabricated.

Falorni calls this genre of film a 'narrative documentary', though, as we know, most documentaries are narrative in one or the other way. In fact, The Story of the Weeping Camel makes up a genre in its own right, one in which fiction enters in perfect symbiosis with fact. This total realism, through which technology comes second to the idea, is, however, not meant to be experienced as complete illusionism at the point of exhibition and reception, but to be recognised as such at the point of the film's production. No matter how much construction and editing reduced the 23 days of shooting to the final 86-minute film, its core event of truth, the mother camel who, to the sound of music, finally sheds tears and accepts her initially rejected colt, provides an unpredictable and undeniable proof of the reality of an ancestral legend, which, as such, brings the film back to the moment when it had not yet been invented.

\section{Bibliography}

Baudry, Jean-Louis (1986), 'The Apparatus: Metapsychological Approaches to the Impression of Reality in the Cinema', in: Philip Rosen (ed.), Narrative, Apparatus, Ideology: A Film Theory Reader. New York: Columbia University Press, pp. 299-318.

Bazin, André (1967), 'The Myth of Total Cinema', in What Is Cinema? Vol. 1, essays selected and translated by Hugh Gray. Berkeley/Los Angeles/London: University of California Press, pp. 17-22.

Bordwell, David, Janet Staiger and Kristin Thompson (2006), The Classical Hollywood Cinema: Film Style \& Mode of Production to 196o. London: Routledge.

Chang, Maria Laura (2019), 'Pájaros de Verano: de las mujeres wayuu y la marimba', in: Cineoculto, https://cineoculto.com/2019/05/pajaros-de-verano-de-las-mujereswayuu-y-la-marimba/ (accessed 13 April 2020).

Dalle Vacche, Angela (2020), André Bazin's Film Theory: Art, Science, Religion. Oxford/New York: Oxford University Press.

Girish, Devika (2019), 'Brazil in a Black Mirror: How Bacurau Turns the Western on Its Head', https://www.bfi.org.uk/news-opinion/news-bfi/interviews/lff63-kleber-mendonca-filho-bacurau (accessed 13 April 2020).

Gunning, Tom (2011), 'The World in Its Own Image: The Myth of Total Cinema', in: Dudley Andrew and Hervé Joubert-Laurencin (eds.), Opening Bazin:Postwar Film Theory and Its Afterlife. Oxford/New York: Oxford University Press, pp. 119-126. 
Harper, Graeme and Jonathan Rayner (2010), 'Introduction: Cinema and Landscape', in: Grame Harper and Jonathan Rayner (eds.), Cinema and Landscape. Bristol/ Chicago: Intellect, pp. 13-28.

Hassan, Feroz (2017), 'Total War, Total History, Total Cinema: André Bazin on the Political Perils of Cinematic Realism', in: Screen, vol. 58, 1, Spring, pp. 38-58.

Kant, Immanuel (1914), Kant's Critique ofJudgement, translated with Introduction and Notes by J.H. Bernard, $2^{\text {nd }}$ edition revised. London: Macmillan, available on https://oll.libertyfund.org/titles/kant-the-critique-of-judgement (accessed 15 April 2020).

Lefebvre, Martin (2006), 'Between Setting and Landscape in the Cinema', in: Martin Lefebvre (ed.), Landscape and Film. New York/London: Routledge, pp. 19-60.

Leotta, Alfio (2018), 'Total Cinema: René Barjavel and the Future Forms of Film', in: Screen, vol. 59, 3, Autumn, pp. 372-38o.

Mathew, Shaj (2019), 'Traveling Realisms, Shared Modernities, Eternal Moods: The Uses of Anton Chekhov in Nuri Bilge Ceylan's Winter Sleep', in: Adaptation, vol. 12, 1, pp. 12-26, DOI: 10.1093/adaptation/apzoo8.

Molica, Fernando and Bruna Motta (2019), 'Kleber Mendonça Filho: "Não fiz um panfleto”', in: Veja, 27 September, https://veja.abril.com.br/entretenimento/ kleber-mendonca-filho-bacurau/ (accessed 13 April 2020).

Plato (n/d), Republic, in:Plato: The Complete Works, translated by Benjamin Jowett. eBooks@Adelaide, Kindle Edition.

Rancière, Jacques (2020), Le temps du paysage: Aux origines de la révolution esthétique. Paris: La fabrique.

St Ours, Kathryn (2011), 'An Ecocritical Study of The Story of the Weeping Camel', in: Interdisciplinary Studies in Literature and Environment, 18.2, Spring, pp. 396-412, DOI: $10.1093 /$ isle/isro45.

Vassilieva, Julia (2018), 'Russian Leviathan: Power, Landscape, Memory', in: Film Criticism, vol. 42, 1, March, DOI: http://dx.doi.org/10.3998/fc.13761232.0042.101.

Winter, Jessica (2004), 'The Camel Stays in the Picture', on: https://www.theguardian. com/film/2004/jul/02/2 (accessed 7 November 2019).

Yacavone, Daniel (2015), Film Worlds: A Philosophical Aesthetics of Cinema. New York: Columbia University Press. 